\title{
Use of Rice Husk Ash (RHA) as a Supplementary Cementitious Material in Producing Normal Concrete
}

\author{
Kazi islam ${ }^{1}$ and Zahid Hossain ${ }^{1, *}$ \\ ${ }^{1}$ College of Engineering, Arkansas State University, PO Box 1740, LSW\#246, State University, Jonesboro, AR 72467, USA
}

\begin{abstract}
With the continuous increase of scarcity of the natural construction material sources and environmental awareness, utilization of wastes/by-products in the construction industry has become an attractive field of study. Several industrial by-products produced from different manufacturing processes have been considered for various usages in the construction field. This paper briefly describes the potential use of Rice Husk Ash (RHA) as Supplementary Cementitious Materials (SCM). Here, three different grades of RHA (600-RHA, 150-RHA, and 44-RHA) in two different percentages (10\% and $20 \%)$ of replacement of Type I Ordinary Portland Cement (OPC) were investigated. Laboratory tests on the fresh concrete mix as well as the mechanical properties of the hardened concrete were performed. It was observed that coarser RHA-modified concrete (600-RHA and 150-RHA) showed reduced strength properties while finer RHA (44-RHA) exhibited improved concrete properties. Moreover, the incorporation of RHA in concrete was found to be effective in mitigating alkaline expansion.
\end{abstract}

\section{Introduction}

The process of urbanization and the scale of construction have increased drastically over the past last few decades. The continuous growth of need for construction materials is causing a huge depletion on the natural resources, which eventually results in an adverse effect on the ecosystem. Among all types of construction materials, concrete is the most widely used construction material. In 2016, 94 million tons of cement were produced all over the US [1]. Moreover, in 2017 the annual growth rate of cement consumption in the US was measured as $2.6 \%$ [1]. In addition, cement production has been contributing significantly to the global carbon emission. It has been reported that the cement industry alone accounts for $5 \%$ of the global $\mathrm{CO}_{2}$ emission [2]. Therefore, the search for finding sustainable sources for construction materials has become a burning need. To this end, rice husk/hull ash (RHA) can be a potential alternative source of cementitious materials.

Over 9 million tons of rice were produced in 2016 [3] which eventually generated about 0.36 million tons of RHA in the milling process. Chemically, RHA contains a high percentage of silica content $\left(\mathrm{SiO}_{2}\right)$ which determines the reactive pozzolanic property [4]. RHA also possesses microporous cellular structures, which facilitate to occur more pozzolanic reactions in presence of Portland cement [5]. In the hydration process, a secondary Calcium-Silicate-Hydrate (C-S-H) gel is produced by RHA, which helps to develop strength in the concrete. The research team of this study has conducted a preliminary study on RHA-modified concrete [6]. This study reported that the incorporation of coarse RHA particle (Particle Size: $600 \mu \mathrm{m}$ ) caused less strength development compared to the regular concrete. The used RHA particles were thirteen times coarser than the cement particles. The study also reported that the maximum compressive strength of $10 \% 600$-RHA-modified concrete was $56 \%$ of that of the Control samples. Moreover, the ASR test data revealed that the bulk RHA was very reactive in concrete.

\section{Objectives}

The main objective of this study was to investigate the usage of RHA as a sustainable construction material. The evaluation process included the analysis of RHA modified concrete on basis of strength and durability properties. Moreover, an optimum dose of RHA in concrete was also determined.

\section{Materials and methodologies}

\subsection{Material selection and data collection}

In this study, Ordinary Portland Cement (OPC) has been replaced by RHA. Two different replacement percentages of cement by weight $(10 \%$ and $20 \%)$ have been utilized in the study. Three different sizes of RHA (RHA 1: $600 \mu \mathrm{m}$, RHA 2: $150 \mu \mathrm{m}$, and RHA 3: $44 \mu \mathrm{m}$ ) were evaluated. Moreover, two additional supplementary cementitious materials (SCM), namely,

\footnotetext{
* Corresponding author: mhossain@astate.edu
} 
Class C fly ash (CFA) and silica fume (SF), were also incorporated in this study. A mix design was prepared considering the measured properties of coarse aggregate (CA), fine aggregate (FA), and type-I OPC. Concrete beams and cylinder were prepared from the modified concrete mix and were tested to examine the strength properties of concrete. From the standpoint of durability assessment of modified concrete, alkali-silica reactivity (ASR), deicing chemical tests were also performed.

In this study, CA, FA, and Type-I OPC were collected from a local ready-mix concrete plant. Crushed stone and Stone sand were used as CA and FA respectively. Figure 1 presents different types of RHAs and SCMs which were incorporated in the study. The dark color of 600-RHA and 150-RHA indicates the high percentage of unburnt carbon [7], whereas the grey color of 44-RHA indicates a low percentage of unburnt carbon. The sources of RHA, CFA, and SF along with their descriptions are provided in Table 1.

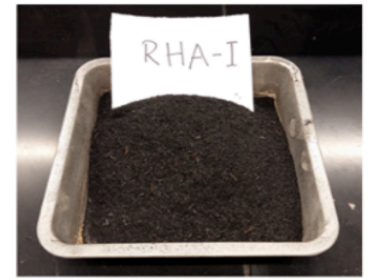

(a)

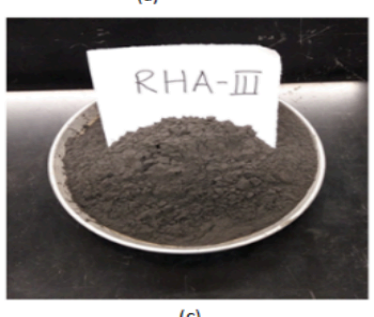

(c)

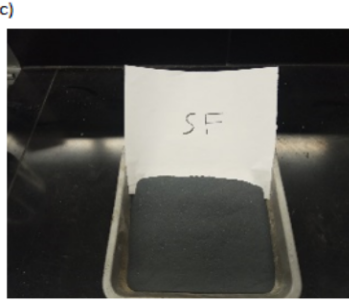

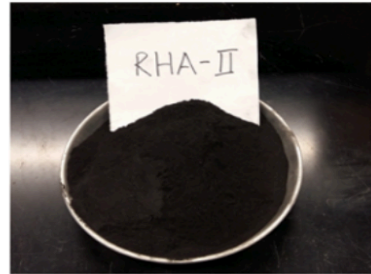

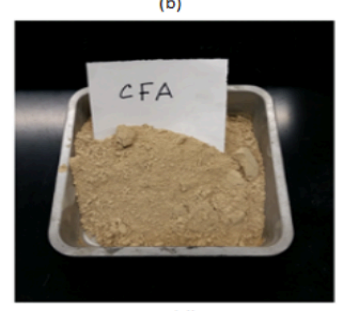

(d)

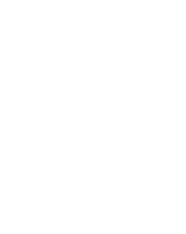

A, (d) CFA,

Fig. 1. (a) 600-RHA, (b) 150-RHA, (c) 44-RHA, (d) CFA, andSF.

Table 1. Source information of RHA, CFA, and SF used in this study.

\begin{tabular}{|c|c|c|}
\hline Material & Description & $\begin{array}{c}\text { Source of } \\
\text { Material }\end{array}$ \\
\hline 600-RHA & $\begin{array}{c}\text { Coarse RHA with a } \\
\text { particle size of } 600 \mu \mathrm{m}\end{array}$ & $\begin{array}{c}\text { Riceland Food, } \\
\text { Inc., Stuttgart, AR }\end{array}$ \\
\hline 150-RHA & $\begin{array}{c}\text { Finer RHA with a } \\
\text { particle size of } 150 \mu \mathrm{m}\end{array}$ & $\begin{array}{c}\text { Riceland Food, } \\
\text { Inc., Stuttgart, AR }\end{array}$ \\
\hline 44-RHA & $\begin{array}{c}\text { Finer RHA with a } \\
\text { particle size of } 44 \mu \mathrm{m}\end{array}$ & $\begin{array}{c}\text { Agrilectric, Lake } \\
\text { Charles, LA }\end{array}$ \\
\hline CFA & $\begin{array}{c}\text { The particle size of } 44 \\
\mu \mathrm{m}\end{array}$ & $\begin{array}{c}\text { Charah Inc., } \\
\text { Louisville, KY }\end{array}$ \\
\hline SF & $\begin{array}{c}\text { The particle size }<1 \\
\mu \mathrm{m}\end{array}$ & Norchem, Inc $-\mathrm{NY}$ \\
\hline
\end{tabular}

The collected physical and chemical data of RHA, CFA, and SF were compared with respect to AASHTO M 321-04 (Standard Specification for High-Reactivity Pozzolans for Use in Hydraulic-Cement Concrete, Mortar, and Grout) and ASTM C 618 (Standard Specification for Coal Fly Ash and Raw or Calcined Natural Pozzolana for Use in Concrete). It was found that all RHA and SF samples met the AASHTO M 32104 specifications for reactive oxides, whereas CFA did not meet the AASHTO M 321 specifications. The CFA met the ASTM C618 specifications for fly ash or natural pozzolan. In addition, mechanical (grinding in a hammer mill) and heat (further burning in a furnace at a high temperature of around $700^{\circ} \mathrm{C}$ ) treatments were conducted on 600-RHA to obtain 150-RHA and 44RHA.

\subsection{Mix design}

As per the American Concrete Institute (ACI) 211.1-91 (the Absolute Volume method) a mix design was developed to prepare the test samples. A service condition of freezing and thawing was also considered in the mix design process. The mix design has a watercement ratio of 0.45 and a slump value of $75 \mathrm{~mm}$. According to the ACI charts, the amount of CA, FA, water, and cement were determined per cubic yard of concrete. Finally, a mix ratio of Type I OPC, FA, and $\mathrm{CA}$ was maintained as $1.0: 1.42: 2.90$ during the preparation of concrete samples.

\subsection{Experimental details}

It can be noted that the specific surface areas of different cementitious materials play a significant role in concrete strength development. As per the ASTM D1993 method, the multi-point Brunauer-EmmettTeller (BET) mode of a NOVA 2200e analyzer was used to measure the specific surface areas of RHAs, SCMs, and Type I OPC. After preparing the concrete mix, the properties of fresh concrete were determined in accordance with ASTM guidelines. The fresh concrete properties, namely, slump, unit weight, and air content were determined according to ASTM C143, ASTM C138, and ASTM C231, respectively.

In the process of determining the hardened concrete properties, concrete cylinders $(150-\mathrm{mm}$ diameter and $300-\mathrm{mm}$ height) and beams (600-mm long with a crosssection of $150-\mathrm{mm}$ by $150-\mathrm{mm})$ were cast in the laboratory. Cylinders and beams were demolded and cured in a water bath, as per the ASTM C31 method. A satisfactory moisture environment during the initial curing was maintained by covering the cylinder specimens with removable plastic lids and the beams by placing inside plastic bags. Upon completion of initial curing and within $30 \mathrm{~min}$ after removing the molds, the final curing of specimens was done by submerging them in water in storage tanks at a room temperature of $25^{\circ} \mathrm{C}$ $\left(77^{\circ} \mathrm{F}\right)$. As per ASTM C39, compressive strengths at 7, 14,21 and 28 days were measured. Splitting tensile strength of the 28-day cured cylindrical sample was 
measured in accordance with ASTM C496. Beam samples were tested for flexural strength of concrete in accordance with the ASTM C293 method. The modulus of elasticity and Poisson's ratio values for cylindrical samples were also determined by using a Universal Testing Machine (UTM) and a compressometer.

The expansions of concrete samples in the presence of alkaline water and reactive aggregates was measured through the alkali-silica reactivity (ASR) test. A linear variable differential transducer (LVDT) was used to measure the expansion readings. The ASR test procedure followed the ASTM C1567 and ASTM C1260 methods. The effect of the deicing chemical on selected concrete samples was estimated through the scaling resistance test (ASTM C305). This freeze-thaw (F-T) cycle was continued for 10 cycles.

\section{Results and discussions}

\subsection{Specific surface area}

The specific surface area of the cementitious material plays a vital role in the development of concrete strength, which directly depends upon the particle size and fineness of the materials [8-10]. It was observed that the specific surface area was increased with the decrease of particle size. The specific surface areas of 600-RHA, 150-RHA, and 44-RHA were found to be $18.038 \mathrm{~m}^{2} / \mathrm{g}, 22.114 \mathrm{~m}^{2} / \mathrm{g}$, and $39.78 \mathrm{~m}^{2} / \mathrm{g}$, respectively. The specific surface areas of the Type-I OPC, CFA, and SF were found to be $47.178 \mathrm{~m}^{2} / \mathrm{kg}, 42.270 \mathrm{~m}^{2} / \mathrm{kg}$, and $22,240 \mathrm{~m}^{2} / \mathrm{kg}$, respectively.

\subsection{Mix properties of fresh concrete}

Table 2, presents the fresh concrete properties for modified concrete mixes. From Table 2, it is seen that Control concrete mix (without SCM) showed a slump value of $90 \mathrm{~mm}$ whereas 600-RHA modified concrete mix resulted in the same slump value of $90 \mathrm{~mm}(10 \%$ 600-RHA) and $115 \mathrm{~mm}$ (20\% 600-RHA), respectively. It was also observed that both $10 \%$ and $20 \% 150$-RHA modified concrete mixes showed a slump value of 25 $\mathrm{mm}$, indicating very low workability. Similarly, $10 \%$ and 20\% 44-RHA modified concrete mixes exhibited slump values of $40 \mathrm{~mm}$ and $50 \mathrm{~mm}$, respectively. On the other hand, CFA exhibited slightly higher slump values than the Control sample.

The air contents of the fresh concrete mixes are also presented in Table 2. The Control mix had an air content of $1.3 \%$. All SCM-modified concrete mixes had higher air contents compared to the Control mix. The $10 \%$ and 20\% 600-RHA modified concrete mixes showed air contents of $2.1 \%$ and $3.2 \%$, respectively. In the case of 44-RHA, the corresponding air contents for $10 \%$ and $20 \%$ RHA were found to be $1.4 \%$ and $2.3 \%$, respectively.

\subsection{Mechanical properties of modified concrete}

The measured mechanical properties of concrete in this study included compressive strength, tensile strength, flexural strength, modulus of elasticity, and Poisson's ratio. Concrete cylinders were cured for up to 28 days to observe the effects of curing on the strength development of concrete. From the laboratory test results (Figure 2), it was observed that 600-RHA and 150-RHA modified concrete exhibited less compressive strength compared to the Control sample. The Control sample showed a compressive strength of $36.1 \mathrm{MPa}$. However, 10\% 600-RHA, 20\% 600-RHA, 10\% 150RHA, and 20\% 150-RHA resulted in compressive strengths of $20.1 \mathrm{MPa}, 16.2 \mathrm{MPa}, 22.8 \mathrm{MPa}$, and 16.8 $\mathrm{MPa}$, respectively. On the other hand, 44-RHA modified concrete showed higher compressive strength than the Control sample. Amounts of $10 \%$ and $20 \% 44-$ RHA exhibited compressive strengths of $37.7 \mathrm{MPa}$ and $36.6 \mathrm{MPa}$, respectively, which were $4.4 \%$ and $1.4 \%$, respectively, higher than the Control sample.

Table 2. Properties of fresh concrete.

\begin{tabular}{|c|c|c|c|c|}
\hline $\begin{array}{c}\text { Type of } \\
\text { RHA/Fly } \\
\text { Ash }\end{array}$ & $\begin{array}{c}\text { Percentage } \\
\text { of } \\
\text { replacement }\end{array}$ & $\begin{array}{c}\text { Slump } \\
\mathbf{( m m )}\end{array}$ & $\begin{array}{c}\text { Air } \\
\text { Content } \\
(\%)\end{array}$ & $\begin{array}{c}\text { Unit } \\
\text { Weight } \\
\left(\mathbf{k g} / \mathbf{m}^{3}\right)\end{array}$ \\
\hline Control & $0 \%$ & 90 & 1.3 & 2435 \\
\hline \multirow{2}{*}{ RHA-1 } & $10 \%$ & 90 & 2.1 & 2259 \\
\cline { 2 - 5 } & $20 \%$ & 115 & 3.2 & 2179 \\
\hline \multirow{2}{*}{ RHA-2 } & $10 \%$ & 25 & 3.4 & 2323 \\
\cline { 2 - 5 } & $20 \%$ & 25 & 3.5 & 2275 \\
\hline \multirow{2}{*}{ RHA-3 } & $10 \%$ & 40 & 1.4 & 2371 \\
\cline { 2 - 5 } & $20 \%$ & 50 & 2.3 & 2323 \\
\hline \multirow{2}{*}{ CFA } & $10 \%$ & 125 & 5.5 & 2355 \\
\cline { 2 - 5 } & $20 \%$ & 125 & 5.8 & 2355 \\
\hline \multirow{2}{*}{ SF } & $10 \%$ & 125 & 5 & 2387 \\
\cline { 2 - 5 } & $20 \%$ & 75 & 5.5 & 2291 \\
\hline
\end{tabular}

Similarly, from Figure 3, it is observed that RHA-3, CFA, and SF modified concrete samples showed more tensile strength than the Control sample. It is evident from Figure 3 that 10\% RHA-3, 10\% CFA, and 10\% SF resulted in $26 \%, 45 \%$, and $25 \%$ more tensile strength compared to the Control sample where 10\% RHA-1, $10 \%$ RHA-2, 20\% RHA-1, and 20\% RHA-2 yielded about $96 \%, 97 \%, 75 \%$, and $88 \%$, respectively, of that of the Control sample.

From the ASR test results (Figure 4), it was observed that both $10 \%$ and the $20 \%$ 600-RHA modified mortar bars exhibited higher expansion compared to the ASTM C1567 recommended limit. In the case of 150-RHA, both percentages of RHA also exhibited expansion more than the ASTM recommended limit.

In this study, 44-RHA not only met the ASTM specified limit but also showed less expansion compared to the Control bar. The 44-RHA mortar bar mitigated ASR expansion by $81 \%$ and $40 \%$ for the $10 \%$ and $20 \%$ replacement levels, respectively, compared to the Control sample. The use of RHA-3 might have generated sufficient C-S-H gel to react with the alkali cations. Thus, the alkali to silica reaction might have been reduced and mortar bar showed less expansion than the Control mortar bar. 


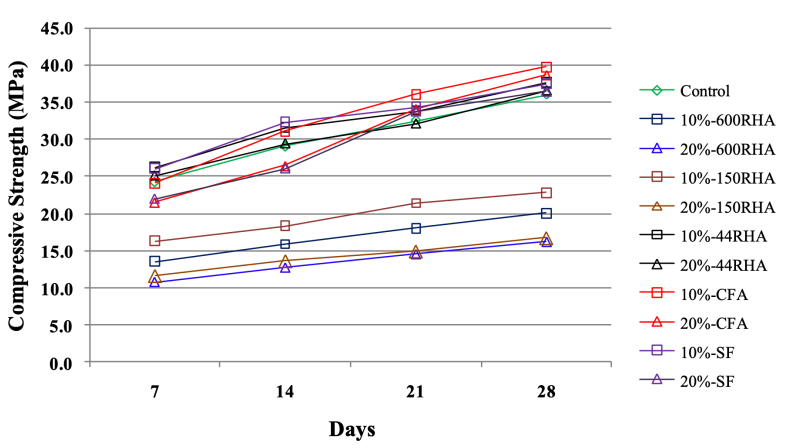

Fig. 2. Compressive strength of different types of modified concrete.

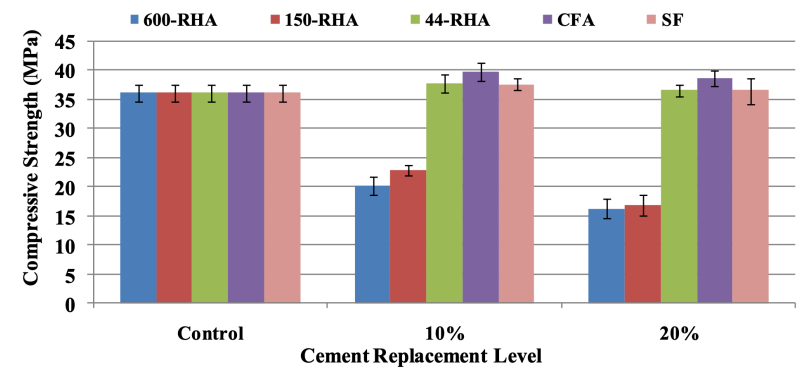

Fig. 3. Comparison of tensile strengths of modified concrete.

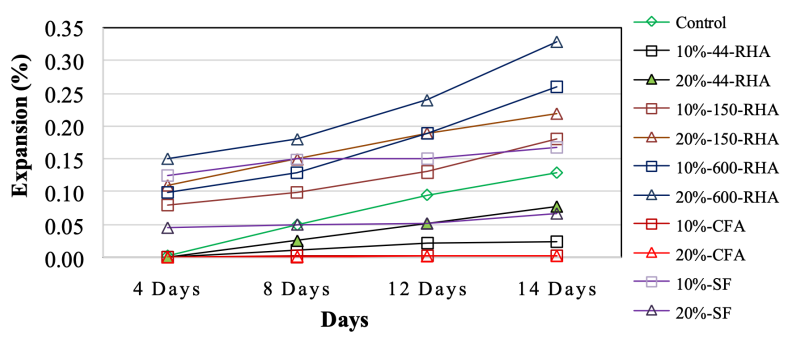

Fig 4. Effect of ASR on modified mortar bars.

\section{Conclusions}

As far now rice husk ash (RHA) has mostly been considered as an agricultural waste material. Different research studies have been conducted to assess the potential use of RHA as a supplementary cementitious material (SCM). In this experimental study, a series of laboratory experiments including the physical and chemical properties of raw materials, workability of fresh concrete, and strength properties of hardened concrete samples were executed. The finer RHA (44RHA) modified concrete mixes exhibited a very low slump value indicating a very stiff and less workable concrete mix. Therefore, it can be concluded that finer RHA incorporated mix require more water to have a similar consistency to the Control sample mix. From the hardened concrete test results, it was found that 600 RHA and 150-RHA in concrete decreased the compressive strength. On the other hand, 44-RHA, CFA, and SF-modified concrete showed greater compressive strength than the unmodified (Control) concrete. Durability test results of modified concrete samples revealed that 44-RHA, CFA, and SF were effective in mitigating the concrete expansion. Thus, considering outcomes of all test results, a 10\% 44-RHA was found to be the best choice among all types and dosages of RHA investigated in this study.

The authors would like to acknowledge the financial support from the Transportation Consortium of South-Central States (Tran-SET). The authors are also grateful to NEAR Concrete, Agrilectric, Riceland Foods, Charah Inc., and Norchem, for providing test materials for this study.

\section{References}

1. Statista (2018). Apparent cement consumption in the U.S. from 2004 to 2017, Forecast of annual cement consumption growth in the U.S. from 2015 to 2018 (in 1,000 metric tons), https://www.statista.com/statistics/273367/consum ption-of-cement-in-the-us/. Accessed May 5, 2018

2. Rebenstein, M. (2012). Emissions from the cement industry, http://blogs.ei.columbia.edu/2012/05/09/emissions -from-the-cement-industry/ Accessed July 2, 2018.

3. USDA (2018). Total U.S. rice production, US Department of Agriculture, National Agriculture Statistics Service, https:/www.statista/190470/total-us-riceproduction-from-2000/,Accessed July 2, 2018.

4. Malhotra, V.M., and Mehta, K.P. (1996). Pozzolanic and cementitious materials. Gordon and Breacch Publ, Canada, 191.

5. Cordeiro, G.C., Filho, T.R.D., and de Moraes, R.F.E. (2009). Use of ultrafine rice husk ash with high-carbon content as pozzolan in high performance concrete. Mater Struct, 42: 983., Springer https://doi.org/10.1617/s11527-008-9437-z

6. Ahsan, M.B., and Hossain, Z. (2018) Use of Rice Husk Ash (RHA) as a Sustainable Cementitious Material for Concrete Construction. In: Struble L., Tebaldi G. (eds) Materials for Sustainable Infrastructure. GeoMEast 2017. Sustainable Civil Infrastructures. Springer, Cham

7. Venkatanarayanan, H.K., and Rangaraju, P.R. (2013). Material Characterization Studies on Lowand High-Carbon Rice Husk Ash and Their Performance in Portland Cement Mixtures. Advances in Civil Engineering Materials, 2(1), 266-287, doi:10.1520/ ACEM20120056. ISSN 2165-3984.

8. Givi, A.N., Rashid, S.A., Aziz, F.N.A. and Salleh, M.A.M. (2010). Contribution of rice husk ash to the properties of mortar and concrete: a review. Journal of American Science, (2010), 6(3), 157 165.

9. Habeeb, G.A., and Mahmud, H.B. (2010) Study on properties of rice husk ash and its use as cement replacement material. Materials Research, 13(2), 185-190. 
10. El-Dakroury, A., and Gasser, M.S. (2008) Rice husk ash (RHA) as cement admixture for immobilization of liquid radioactive waste at different temperatures. Journal of Nuclear Materials, 381(3), 271-277. 